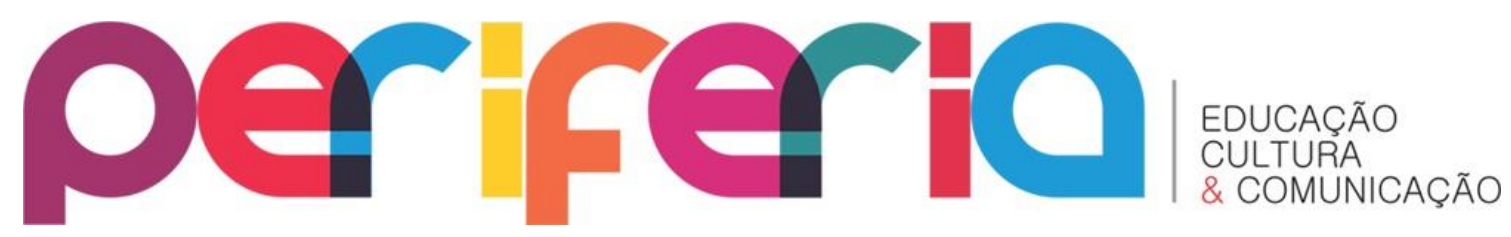

\title{
EM BUSCA DA HISTORICIDADE DO MUNICÍPIO DE QUEIMADOS: EXPERIÊNCIAS POSSÍVEIS ENTRE A HISTÓRIA PÚBLICA E O ENSINO DE HISTÓRIA
}

Claudia Patrícia de Oliveira Costa Correio ${ }^{1}$

Secretaria de Estado de Educação do Rio de Janeiro

\section{RESUMO}

Durante as entrevistas realizadas junto à população queimadense entre os anos de 2009 e 2013, identificamos significativo desconforto revelado diante do desenvolvimento da cidade. Tal desconforto expressou-se, na fala dos entrevistados, a partir do crescente interesse dos depoentes em compartilhar suas memórias, registrando-as como "uma resposta ou reação, diante das mudanças rápidas e de uma vida sem âncoras ou raízes" (JELIN, 2002, p. 9). Nesse sentido, constatamos que a preocupação de muitos queimadenses, especialmente aqueles cujas trajetórias de vida se caracterizaram pela maior atuação na esfera pública, introduz questões como a importância das memórias para a escrita e o ensino de História, sua divulgação, a patrimonialização cultural e a dívida do presente com o passado.

Palavras-chave: Ensino de História; história pública; memória; Queimados

\section{A QUEST FOR THE HISTORY OF QUEIMADOS CITY: EXPERIENCES IN BETWEEN THE PUBLIC HISTORY AND HISTORY TEACHING ABSTRACT}

Upon having citizens of Queimados interviewed between 2009 and 2013, a significant discomfort with the growth of the city was identified. Such discomfort was expressed on the speech of those interviewed. The citizens had a growing interest in sharing their memories, which would be "a response or reaction on the quick changes of the city and a life with no roots" (JELIN, 2002, p. 9). At this point, we conclude that it is the concern of many Queimados citizens (especially those with a greater role publically), that the citizens' memories must be seen as an important part of history teaching, history disclosure, a cultural patrimony and the present's debt with the past.

Keywords: History teaching; public history; memories; Queimados

\footnotetext{
${ }^{1}$ Doutoranda em História Social junto à Faculdade de Formação de Professores da Universidade do Estado do Rio de Janeiro (FFP/UERJ). Pesquisadora do Laboratório de Estudos em Ensino de História e Patrimônio Cultural da Pontifícia Universidade Católica do Rio de Janeiro (LEEHPaC/PUC-Rio). Professora de História da rede pública estadual do Rio de Janeiro. E-mail: cliouerj@yahoo.it
} 


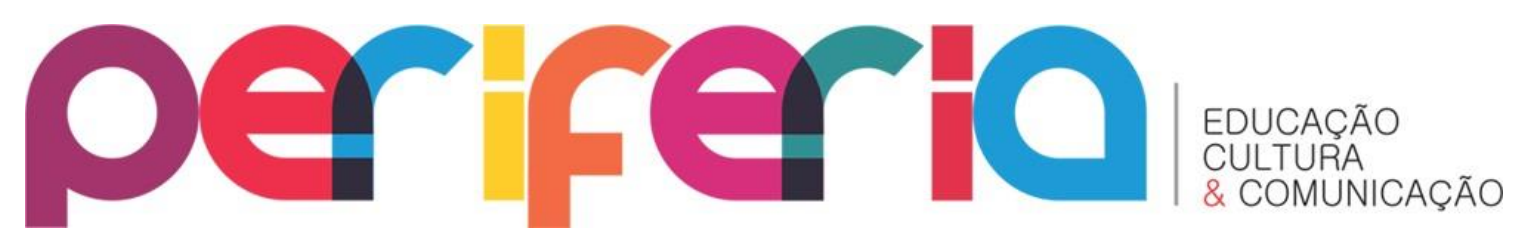

\section{INTRODUÇÃO}

Situamos o início de nosso trabalho no ano de 2009, a partir de registros audiovisuais de depoimentos e histórias de vida colhidos junto à parte da população mais antiga da cidade de Queimados, na Baixada Fluminense ${ }^{2}$. Com pouco mais de duas décadas decorridas desde a conquista da emancipação desse município, ao realizarmos tais entrevistas observamos um empenho coletivo da população queimadense em compartilhar suas memórias, o que nos instigou a continuar o trabalho. Ainda de acordo com tais vozes registradas, identificamos um crescente interesse em remexer as memórias e buscar "uma resposta ou reação, diante das mudanças rápidas e de uma vida sem âncoras ou raízes" (JELIN, 2002, p. 9). A partir dos argumentos introduzidos por Elizabeth Jelin, inferimos que a "vida sem âncoras ou raízes" se insere na perspectiva da aceleração da vida contemporânea, incômodo expresso na maioria das entrevistas concedidas a nós por antigos queimadenses. Para o historiador Fernando Catroga, a contemporaneidade, na medida em que traz consigo a dissolução das sociabilidades mais tradicionais, pode provocar um esforço pela unificação e coesão de memórias com o objetivo de reagir aos sentimentos de fragmentação, esquecimento e fugacidade experimentados (CATROGA, 2001, p. 56). De fato, entendida pela fala de alguns entrevistados, como um movimento inexorável e avassalador de modernização, a contemporaneidade traz em si uma gama de questionamentos acerca da extensão desse fenômeno e de seus impactos positivos e negativos sobre a cidade. Apostamos nessas reflexões e, por acreditarmos na possibilidade de uma escrita da história para Queimados que dê conta dessas inquietações, esse projeto apontou-nos variados e desafiadores caminhos a trilhar.

Dentre esses caminhos, destacamos aqui as possíveis conexões entre essa pesquisa e o ensino de História. A partir de nossas experiências em ambos os campos, consideramos que essa conexão se configura uma forma de dar conta de expectativas que se entrecruzam e se complementam: dar a conhecer trajetórias de vida de

\footnotetext{
2 Para a realização desses registros, foi indispensável a atuação do professor Nilson Henrique de Araujo Filho na intermediação dos contatos com os depoentes e na realização dos roteiros que nortearam as entrevistas.
} 


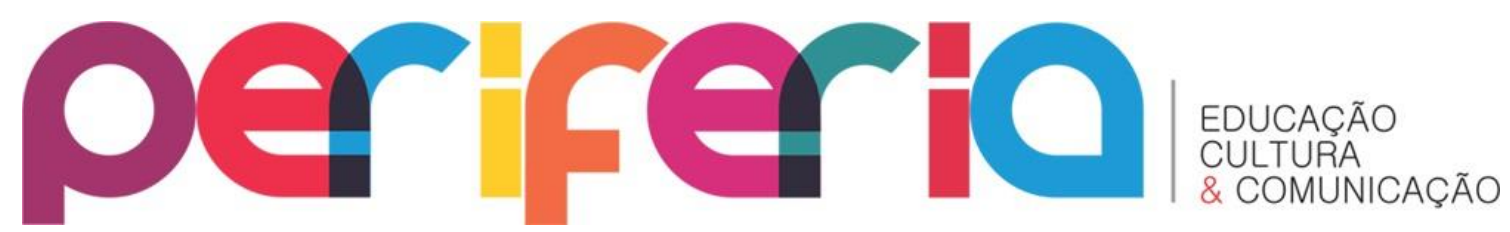

pessoas, ditas comuns, e seus esforços autobiográficos de perpetuação das memórias de uma cidade que não mais existe, além da reivindicação do reconhecimento público por ações passadas que, na opinião dos entrevistados, devem ser referenciadas no presente. A mediar tais expectativas, evocamos o potencial inaugurado pela ampliação dos debates que concernem à História Pública no Brasil.

A História Pública, como conceito, surgiu a partir de eventos realizados no meio acadêmico anglo-saxônico na década de 1970. Desde então, tem ganhado cada vez mais espaço nos debates que buscam alternativas que proponham o estreitamento de laços entre o saber histórico, produzido em centros de pesquisa e universidades, e o público mais amplo. A proposta da História Pública tem encontrado repercussões positivas entre os países anglófonos, como Estados Unidos, Canadá, Austrália e África do Sul. Também são significativos os avanços, nesse campo, na Itália. No Brasil, destacamos a formação da Rede Brasileira de História Pública (RBHP), criada em meio aos debates que tiveram lugar na Universidade de São Paulo (USP), a partir da presente década ${ }^{3}$. Com base nessa constatação, percebemos que as discussões acerca da História Pública, no Brasil, apesar de recentes, vêm se dinamizando com o passar dos anos, traduzindo-se no fomento de eventos e organização de publicações sobre a temática, buscando aproximações possíveis entre a academia e o público mais amplo.

Segundo o historiador norte-americano Robert Kelley (1992, p. 111, tradução nossa), a História Pública "se refere ao trabalho de historiadores e ao emprego de métodos historiográficos fora da academia: no governo, em empresas privadas, nas mídias, em sociedades históricas e museus". Para esse pesquisador, um dos precursores da História Pública, dentre os caminhos para atingir os objetivos de um projeto que ambicione alinhar-se às práticas intrínsecas a essa proposta estão as abordagens pluridisciplinares. A concordar com tal abordagem, destaca-se a historiadora inglesa Jill Liddington. Para ela, o trabalho em parceria com outros profissionais, como bibliotecários, arquivistas, jornalistas ou web designers, propicia ao

\footnotetext{
${ }^{3}$ Sobre a atuação da RBHP, ver: http://historiapublica.com/
} 


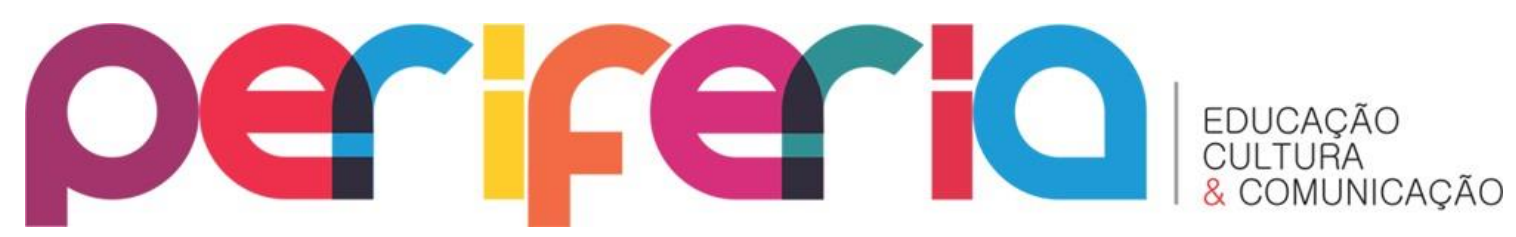

historiador ampliar e enriquecer suas práticas a partir das trocas de experiências e saberes. Liddington (2011, p. 47) argumenta, ainda, que, enquanto esses profissionais "ganham acesso a uma experiência acadêmica crucial, em um tema ou em um período, o ganho dos historiadores inclui técnicas de produção melhoradas e alcance público mais amplo". De tal forma, acreditamos que um dos escopos da História Pública é repensar a escrita da história, enfatizando suas conexões com o tempo presente, com as disputas e tensões cotidianas, buscando romper o caráter de "relíquias de antiquário", assumido durante muito tempo pela própria história como disciplina.

Entretanto, o conceito que, em um primeiro momento pode parecer simples e muito abrangente, envolve questões tanto históricas quanto éticas que o tornam bem mais complexo e um terreno que fomenta acaloradas discussões. O surgimento do conceito de História Pública é permeado por questões que ainda estão longe de se esgotarem. De acordo com a professora Sara Albieri, as tensões entre público e privado, postas em evidência no bojo da contemporaneidade, se constituem em um contexto indissociável da emergência de iniciativas no campo da História Pública. O interesse das pesquisas históricas, renovado pela abertura de arquivos das ditaduras do Cone Sul, por exemplo, se insere nessa perspectiva. No caso do Brasil, carreados pelo longo e intrincando processo de transição democrática, a abertura e a utilização de tais arquivos colocam em pauta questões que se relacionam ao próprio ideal de cidadania que se buscou implantar no país. A publicização de tais registros torna-se, portanto, uma demanda que não se restringe somente à academia; inclui-se entre as reivindicações de movimentos sociais representativos de grupos que estiveram silenciados, durante muito tempo (ALBIERI, 2011, p. 19). Por outro lado, o próprio surgimento dos debates acadêmicos sobre a História Pública, situados na década de 1970, dialoga em grande medida com o chamado "giro linguístico" ${ }^{4}$ ou com sua outra

\footnotetext{
4 Segundo Javier Gil Pujol, o chamado "retorno linguístico" (linguistic turn) se insere no contexto da reabilitação da História Política, em face ao "fracasso ou esgotamento da prática historiográfica seguida pelos Annales e pela história marxista" Destacamos, todavia, que esse retorno à narrativa introduziu questionamentos e críticas, distanciando-se daquela perspectiva antiga, na qual a narrativa visava o mero relato, tido como forma de revivificar o fato (PUJOL, 1983, p. 68-69).
} 


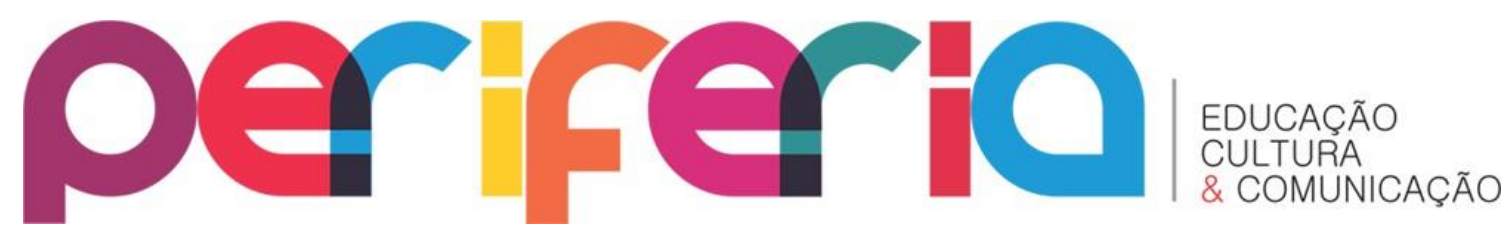

face, a "guinada subjetiva"5. Esses movimentos marcaram, nos meios acadêmicos, a partir da mesma década de 1970, a retomada de fôlego das narrativas e, com elas, a investigação das subjetividades.

A caminhar com o "giro linguístico" e os estudos sobre as subjetividades, destaca-se o interesse pelas memórias, abordadas em suas dimensões social e política. O estudo das memórias, segundo essas perspectivas, tem se configurado em uma instigante chave para a produção de trabalhos no âmbito da História Pública. Portadoras de temporalidade disjuntiva, os processos que envolvem os trabalhos da memória, definidos com notável propriedade por sociólogos como Michael Pollak (1989; 1992) $)^{6}$ e Elizabeth Jelin $(2002)^{7}$, fazem com que os atos de ouvir e analisar narrativas tornem-se propostas profícuas em direção ao estreitamento de relações entre o saber acadêmico e as comunidades que compartilham essas memórias. Esse interesse aponta para a possibilidade de fomento de projetos que procurem articular a história em suas esferas global e local, traduzindo-se em discursos historiográficos que não percam o rigor da produção científica, mas que, por outro lado, promovam a

\footnotetext{
5 "A ideia de entender o passado a partir de sua lógica (uma utopia que moveu a história) emaranha-se com a certeza de que isso, em primeiro lugar, é absolutamente possível, o que ameniza a complexidade do que se deseja reconstituir; e, em segundo lugar, de que isso se alcança quando nos colocamos na perspectiva de um sujeito e reconhecemos que a subjetividade tem um lugar, apresentado com recursos que, em muitos casos, vêm daquilo que, desde meados do século XIX, a literatura experimentou como primeira pessoa do relato e discurso indireto livre: modos de subjetivação do narrado. (...) São passos de um programa que se torna explícito, porque há condições ideológicas que o sustentam. Contemporânea do que se chamou, nos anos 1970 e 1980 de 'guinada linguística' ou muitas vezes acompanhando-a como sua sombra, impôs-se a guinada subjetiva" (SARLO, 2007, p. 18).

6 "O trabalho de enquadramento da memória se alimenta do material fornecido pela história. Esse material pode sem dúvida ser interpretado e combinado a um sem-número de referências associadas; guiado pela preocupação não apenas de manter as fronteiras sociais, mas também de modificá-las, esse trabalho reinterpreta incessantemente o passado em função dos combates do presente e do futuro" (POLLAK, 1989, p. 9, grifo nosso).

7 "O título deste livro alude à memória como trabalho. Por que falar de trabalhos da memória? $\mathrm{O}$ trabalho como traço distintivo da condição humana põe indivíduo e sociedade em um lugar ativo e produtivo. (...) Falar de trabalhos de memória requer que se estabeleçam algumas distinções analíticas. Sem dúvida, alguns fatos vividos no passado têm efeitos em tempos posteriores, independentemente da vontade, da consciência, da ação ou da estratégia dos atores. Isso se manifesta desde planos mais 'objetivos' e sociais (...) até os processos mais pessoais e inconscientes, ligados a traumas. (...) Nessas situações, a memória do passado invade, porém não é objeto de trabalho. A contrapartida dessa presença que não presume ação é a dos seres humanos ativos nos processos de transformação simbólica e de elaboração de sentidos do passado. Seres humanos que 'trabalham' sobre e com as memórias do passado" (JELIN, 2002, p. 14, grifo da autora).
} 


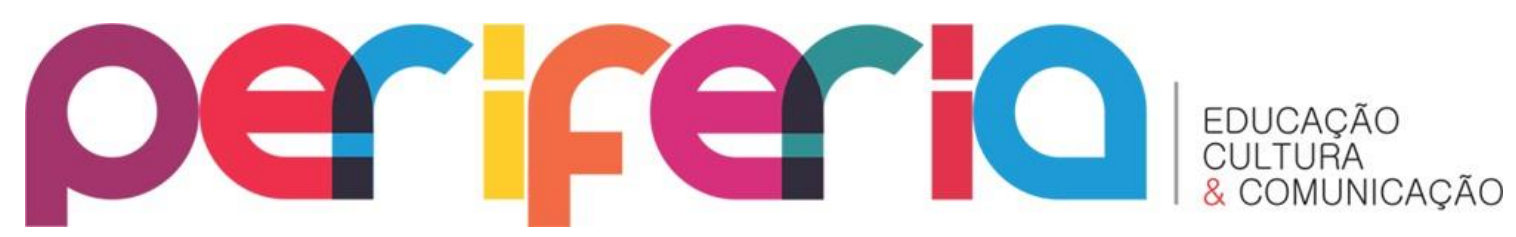

construção, compreensão e difusão de múltiplas identidades, levando em conta especificidades regionais, locais e sociais, entre outras. Consideramos que projetos desse tipo têm muito a contribuir para reconfigurar a própria perspectiva de exercício da cidadania a partir do momento em que se estabeleça um canal interacional entre a história pública e as memórias.

Assim, em concordância com argumentos tecidos por Leonor Arfuch (2010, p. 242), pressupomos que esses registros podem representar o primeiro estágio "em direção à elaboração de um produto-outro". No presente caso, as entrevistas têm representado o ponto de partida para a publicização dessas memórias, fomentando um debate que deve desembocar em uma possibilidade de escrita da história de Queimados que dê voz às "pessoas comuns". Ao nos basearmos em Arfuch, afirmamos que essas entrevistas trazem a marca da chamada "autoria conjunta", isto é, da relação subjetiva estabelecida entre entrevistador e entrevistado. Pensando nesse aspecto, tornou-se premente a necessidade de que fosse aberto um canal de comunicação que possibilitasse a interface entre entrevistados e os "produtos-outros" passíveis de serem obtidos a partir de seus depoimentos. Em um contexto no qual as transformações aceleradas levam ao permanente questionamento acerca do que deve ser guardado ou do que é descartável, a publicização dessas narrativas pode ser o primeiro passo ou a primeira resposta às inquietações e clamores por reconhecimento ou pela superação do esquecimento.

Longe de rejeitarmos a presença maciça da influência midiática nas sociedades contemporâneas, orientamos nossas propostas por meio da apropriação do aparato disponível, notadamente as mídias virtuais, a fim de buscarmos estabelecer canais em que essas memórias e narrativas de vida sejam divulgadas. Essa exposição visa não só ao conhecimento de um público ampliado, com vistas à satisfação dos anseios memorialistas de reconhecimento com base no caráter maciço assumido pela internet. A exposição desses textos se inscreve na perspectiva de oferecer uma resposta ao esforço empreendido pelos sujeitos-objetos da história de Queimados que se disponibilizaram a participar da pesquisa, compartilhando suas histórias de vida. A 


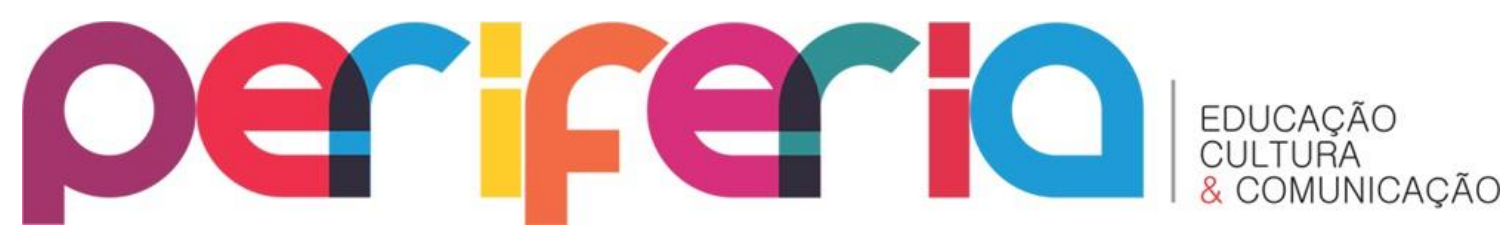

divulgação desses relatos, ou, antes, dos produtos que podem ser obtidos por meio deles, visa criar um canal de debate em que possamos igualmente ampliar os nexos da intersubjetividade e da intertextualidade pressupostos nesse tipo de registro. Assim, ao criarmos espaços virtuais ${ }^{8}$ onde o trabalho com esses registros é divulgado, acreditamos estar em sintonia com uma demanda que, nos dizeres de Leonor Arfuch,

[...] envolve tanto as indústrias culturais como a pesquisa acadêmica, fala simultaneamente de uma recepção multifacetária, de uma pluralidade de públicos, leitores, espectadores, de um interesse sustentado e renovado nos infinitos matizes da narrativa vivencial (2010, p. 15-16).

A temática da publicização dessas narrativas é assunto instigante. O historiador norte-americano Richard Cándida Smith dedicou um capítulo de sua obra intitulada "Circuitos de subjetividade: história oral, o acervo e as artes" à discussão sobre as imbricações entre os relatos orais e a cultura impressa (SMITH, 2012, p. 45-59). Ao longo desse texto, ele destaca diversas questões que perpassam o desafio de transformar os códigos orais em texto escrito, evitando os custos da perda de sua autenticidade e especificidade. Ao discutir exemplos de publicações realizadas nessa área, Smith chama-nos a atenção para a inevitabilidade da alienação das fontes, quando o resultado de um trabalho com fontes orais é transposto para o papel e publicado. O entrevistador deixa de ser o destino imediato da entrevista e o pacto firmado entre ele e seu entrevistado se amplia com a participação dos leitores. 0 processo de alienação das fontes potencializa-se, tornando-se mesmo inevitável, perante essa perspectiva. Diante da ameaça ao rigor acadêmico ou à seriedade da pesquisa, representadas por essa constatação, Richard Smith afirma que, ao manter as confusões e contradições intrínsecas ao testemunho oral, descortinam-se, perante o

\footnotetext{
${ }^{8}$ Quando nos referimos aos "espaços virtuais", citamos o blog Memória, Pesquisa e Patrimônio Histórico de Queimados e correlato perfil na rede social Facebook, ambos criados no ano de 2010, em parceria com o professor Nilson Henrique de Araújo Filho, também pós-graduado em História do Rio de Janeiro e professor de história na Educação Básica. Cf. http://www.memoriaqueimados.blogspot.com e https://www.facebook.com/patrimonio.queimados, respectivamente. Mais recentemente, foi criada página, junto à mesma rede social, disponível no endereço: https://www.facebook.com/memoriaqueimados
} 


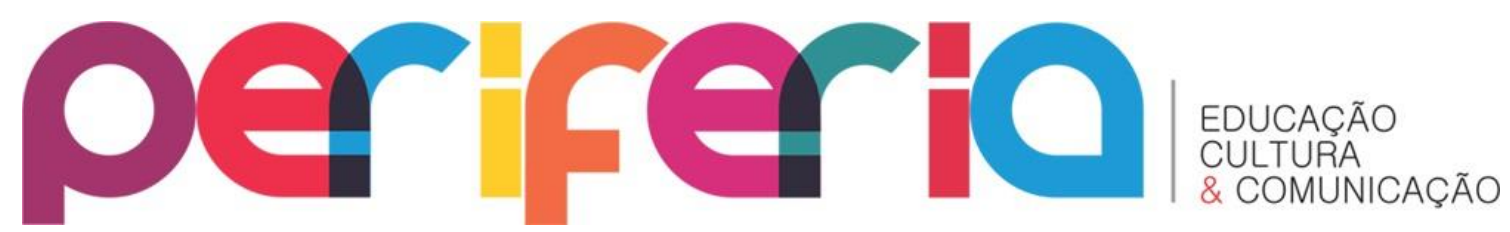

pesquisador-entrevistador, aspectos que exigem reflexões que devem ser estendidas aos leitores, convidando-os a participar das considerações elaboradas pelo pesquisador a partir das falas dos entrevistados. Nesse sentido, "a compreensão não é o propósito de transformar o passado em história, mas o posicionamento de si mesmo em relação aos outros no presente" (SMITH, 2012, p. 57).

Ao concordarmos com as ilações de Richard Smith, acreditamos que a utilização dos referidos espaços virtuais potencializa o "posicionamento de si mesmo em relação aos outros no presente", na medida em que amplia exponencialmente o alcance das informações e o acesso dos leitores. Inegavelmente, o acesso à internet e a utilização sistemática de redes sociais virtuais se impõem a cada dia, criando e consolidando novos tipos de sociabilidade. Ao inserir o trabalho com as entrevistas sobre a emancipação de Queimados nessa perspectiva, não perdemos de vista a natureza historiográfica da pesquisa. Durante os quatro anos de funcionamento, o blog e os perfis sobre nossas pesquisas no município de Queimados têm se consolidado como espaços de divulgação dos resultados desse trabalho e de discussão, troca de experiências e informações sobre as memórias da população queimadense. A síntese dos depoimentos colhidos é veiculada nesses espaços virtuais juntamente com fotografias atuais ou antigas, quase sempre cedidas pelos próprios depoentes. A repercussão dessas postagens tem sido bastante instigante, na medida em que os visitantes do blog e seguidores do perfil têm ali um espaço para comentar, opinar ou acrescentar histórias àquelas já contadas, como podemos exemplificar a partir dos comentários a seguir:

Achei o trabalho interessante. Sou moradora do município e graduanda do Curso de História. Como posso contribuir e fazer parte dessa pesquisa? (Cristiane Lucas, em 31/08/2010).

Blog $\mathrm{mt}$ bom![sic] É um bom começo para criarmos um acervo rumo a um museu com a história da cidade. Vamos buscar as famílias mais antigas de nossa cidade e conseguir fotos que podem enriquecer esse acervo [sic]. A prefeitura deveria criar uma secretaria formada por historiadores do município e empenhados nessa missão (Nelson Costelha, em 23/10/2011). 


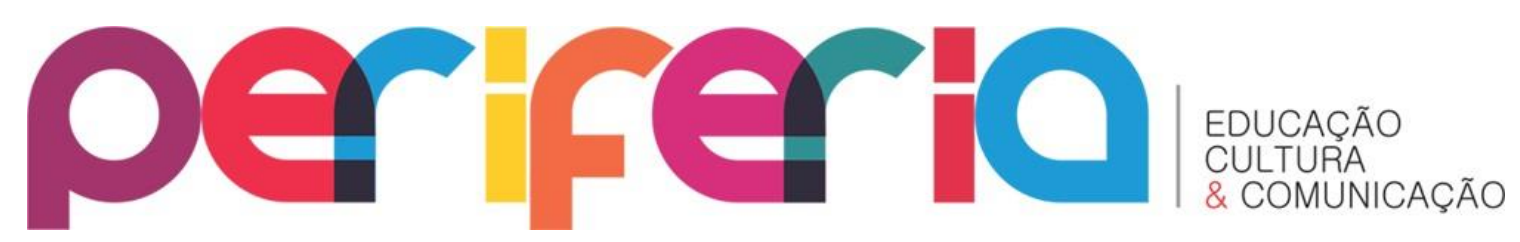

Gostei muito desse blog. Resgata a história de Queimados que poucos conhecem e traz uma nova visão do município para o cidadão, para que este possa valorizar a história e outros aspectos que andam um tanto esquecidos (Rafaela, em 09/07/2011).

Parabéns, professores Claudia e Nilson! Precisamos resgatar nossas histórias para sabermos como chegamos aqui, conhecer melhor nossas identidades e valorizar nosso presente e nosso futuro. Não sou de Queimados, mas trabalho na rede como professora de Educação Física. Sugiro que sejam feitos resgates dessa natureza nas escolas de Queimados e também de outras práticas. Se me permitem, vou passar adiante essas informações com os devidos créditos. Visitem o blog da escola Washington Manoel. Abraços (Denise Guerra, em 05/06/2011).

O importante é que vocês têm perfeita consciência do momento que estão vivendo. Levantar o problema já é solução para o problema. As dúvidas e incertezas de Queimados são também as dúvidas e incertezas de todas as cidades do Brasil. Ninguém sabe o caminho... $\mathrm{O}$ caminho se faz caminhando. O momento enseja a solução. Sigam realizando esse maravilhoso trabalho que estão realizando. 0 importante é trabalhar, isso vocês já estão fazendo, há muito tempo. Parabéns (Rogério Torres, em 03/11/2012).

Amei conhecer esse blog, revi muitas pessoas que não via há muito tempo, eu tb [sic] faço parte da história de Queimados, nasci lá. Não moro mais em Queimados, mas continuo visitando sempre, ainda tenho muitos parentes em Queimados (Lúcia, em 04/11/2012).

Adorei o trabalho de todos os envolvidos. Patrimônio Queimados pela dedicação com a nosso município [sic], por seu trabalho sério em buscar cada pedacinho da nossa história. Muito legal a família de Vasco Giacometti ter compartilhado suas memórias. Parabéns a todos! Como é bom poder VER [sic] nossa história (Anônimo, em 05/03/2013).

Que bom que esse resgate do nosso passado, nossa história, finalmente está acontecendo! Quem sabe assim nosso povo se valorize mais! (Anônimo, em 05/03/2013).

A partir do retorno garantido por esses comentários, acreditamos poder contribuir para complexificar as possibilidades de abordagem do fenômeno problematizado pelo professor Richard Cándida Smith. Para isso recorremos, mais uma vez, aos argumentos de Leonor Arfuch (2010, p. 21) no que tange às disputas pela 


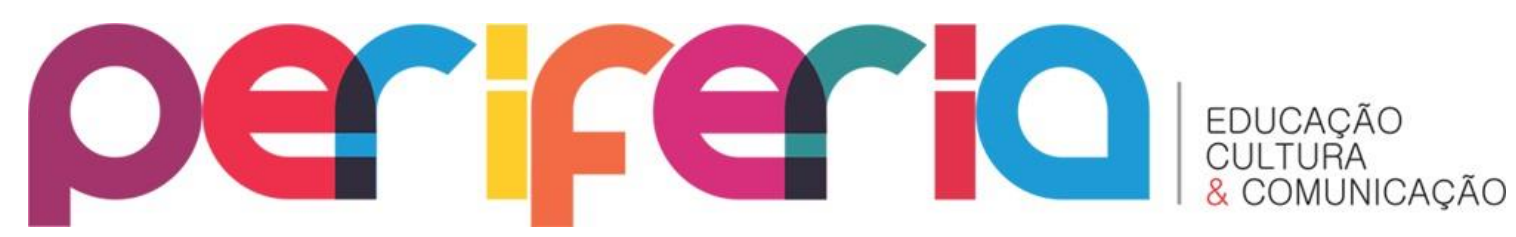

"autenticidade das histórias na voz de seus protagonistas, seja na transmissão ao vivo das câmeras, seja na inscrição da palavra gráfica, pela veracidade que o testemunho impunha ao terreno escorregadio da fiç̧ão".

Ancorados em tal premissa, percebemos que os debates suscitados pela exposição da síntese das entrevistas e os comentários a elas associados colocam ainda mais em evidência as disputas em torno do direito de narrar e da legitimidade das narrativas. Segundo Arfuch, vivemos em uma época de interesse quase obsessivo pelas formas de narrativas biográficas. Para a autora argentina, esse interesse se exacerba nas tramas da cultura contemporânea a partir da proliferação dos gêneros midiáticos, da qual a popularidade dos inúmeros realities shows é um exemplo sintomático. Ao tomarmos a propagação e popularização dos meios virtuais inseridas em tal contexto, o blog, perfil e página na rede social cumprem o duplo papel de dar a conhecer aspectos das memórias queimadenses e captar as versões complementares e aquelas conflitantes, mobilizadas pelas narrativas do público-leitor. Esse público-leitor, majoritariamente composto por queimadenses, interage com as narrativas divulgadas no blog, acrescentando informações, questionando fatos ou reivindicando seu papel de testemunha autorizada ${ }^{9}$ a narrar. Diante de tal constatação, destacamos outro ponto significativo introduzido por essa experiência: o alcance dessas interfaces junto ao segmento mais jovem da população.

Consideramos o amplo domínio das novas tecnologias de comunicação por esse segmento da população como um dado característico daquilo que Arfuch denominou "cultura contemporânea". Sob essa perspectiva, o uso da mídia virtual para divulgação e debate dos resultados parciais obtidos a partir da realização das entrevistas abre espaço para se pensar o uso dessas interfaces como forma de articular a pesquisa e o ensino/aprendizagem da História Local. Admitimos que o uso desses suportes de informação tem se confrontado sistematicamente com o uso de suportes mais tradicionais, como o livro didático, por exemplo. Nesse contexto, a utilização da

\footnotetext{
${ }^{9}$ Para Michael Pollak, para compreender o permanente processo que envolve os trabalhos de memória, “é preciso, portanto, escolher testemunhas sóbrias e confiáveis aos olhos dos dirigentes" (1989, p. 10).
} 


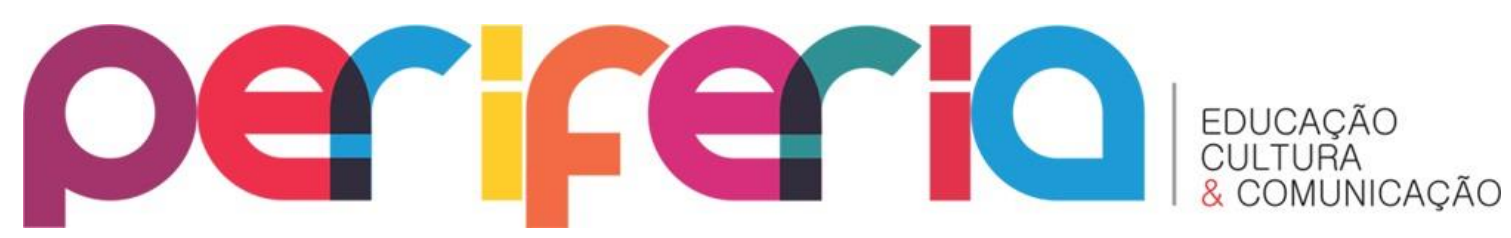

História Oral medeia a relação entre pesquisa, ensino e aprendizagem de forma a contribuir para que sejam aprofundadas reflexões entre educadores e educandos a respeito de sua inserção social em escala local, regional ou nacional. A partir de então, atentamos para o potencial caráter educativo das entrevistas, pois, como defende Arfuch:

[...] o 'retrato' que a entrevista brinda irá, então, para além de si mesmo, dos detalhes admirativos e identificatórios, em direção a uma conclusão suscetível de ser apropriada em termos de aprendizagem. Falando da vida ou mostrando-se viver, o entrevistado, no jogo dialético com seu entrevistador, contribuirá sempre, mesmo sem se propor, para o 'acervo' comum (2010, p. 153, grifo da autora).

Constatar esse potencial no trabalho com entrevistas coloca em questão as contribuições possíveis para o campo da prática pedagógica. Assim, para além de espaço de divulgação dos resultados parciais obtidos por meio da mobilização das entrevistas, o blog e os perfis têm cumprido a função de promover e divulgar eventos como oficinas em escolas, voltadas tanto para professores quanto para alunos; exposições e seminários abertos ao público em geral. Esses eventos sempre se desenvolvem em torno do eixo norteador que é a História Local e as histórias de vida em suas múltiplas interfaces possíveis.

A partir dos comentários de professores da Educação Básica que frequentam os referidos espaços virtuais e relatam-nos suas experiências com seus alunos com base no material disponibilizado, estabeleceu-se uma gama de possibilidades para o estreitamento de relações entre a história produzida na universidade e aquela produzida nas salas de aula da Educação Básica. Entretanto, ao passo que buscamos a articulação da pesquisa ao ensino/aprendizagem de História, percebemos significativos obstáculos para que se estabeleça o necessário diálogo entre o saber acadêmico e o saber construído nas salas de aula. Essa questão se impõe de maneira ainda mais polêmica no que tange à reelaboração dos currículos de História, especialmente na Educação Básica. Os esforços empreendidos nesse sentido inserem-se no contexto da década de 1980, quando 


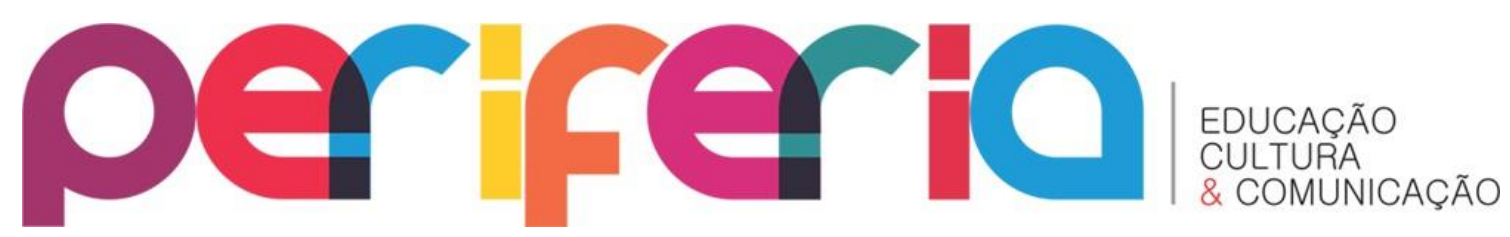

[...] os movimentos sociais em torno da luta pelo fim da ditadura militar e pelo retorno da democracia influenciaram as pesquisas [...] em Educação, os estudos sobre o currículo, notadamente dos currículos para o ensino de História. O período é marcado por um conjunto de propostas de reformulação curricular que, embora diferentes entre si, visavam ressignificar estruturalmente as noções de conhecimento escolar, de uso e de produção desses conhecimentos (SOARES, 2012, p. 617).

Nesse sentido, não mais se trata de legitimar um passado, no intuito de forjar uma identidade nacional única e homogeneizante, como foi perspectiva predominante na historiografia da segunda metade do século XIX e boa parte do século seguinte. Trata-se de contribuir para a construção e compreensão de múltiplas identidades. Conforme Bittencourt, "a constituição de identidades associa-se à formação da cidadania, problema essencial na atualidade" (2008, p. 121).

Inscrevendo-nos nessa chave de análise e, a partir dos esforços anteriormente citados, caminhamos no sentido de propor ações que levem em conta as relações locais, regionais e nacionais; buscou-se instituir uma possibilidade para a escrita da história da cidade ancorada no conceito de escala de observação ${ }^{10}$. Essa proposta encontra-se em consonância aos objetivos do ensino dessa disciplina nos Parâmetros Curriculares Nacionais. Entretanto, na perspectiva dos debates que acompanham a ideia de cidadania no Brasil, a transposição da teoria para a prática não tem sido tarefa simples. Concordamos que "a construção do conhecimento a partir da vivência, portanto, do local e do presente, é a melhor forma de superar a falsa dicotomia entre a produção e a transmissão, entre a pesquisa e o ensino/divulgação, enfim, entre o saber e o fazer" (NEVES, 1997, p. 27). Ao reconhecermo-nos na proposta da pesquisadora Joana Neves, apostamos na História Pública e no papel dos espaços virtuais como possibilidades de reduzir ou mesmo transpor essas barreiras.

\footnotetext{
10 Nesse sentido, concordamos com a historiadora Marcia Gonçalves e acreditamos que "o uso do conceito de escala de observação adquire significação ao viabilizar a construção de uma abordagem requalificadora de adjetivos - nacional, regional, local, individual, macrossocial, microssocial - há muito empregados pelos que gostam de contar histórias. (...) Precisar as fronteiras dos inúmeros espaços sociais nos quais os sujeitos históricos protagonizam seus dramas e misérias humanas é, no nosso ponto de vista, uma das tarefas fundamentais do historiador e pode vir a ser balizada pela escolha de uma escala de observação, desde que a mesma esteja subordinada a um determinado efeito de conhecimento perseguido pelo investigador" (GONÇALVES, 2001, não paginado, grifo da autora).
} 


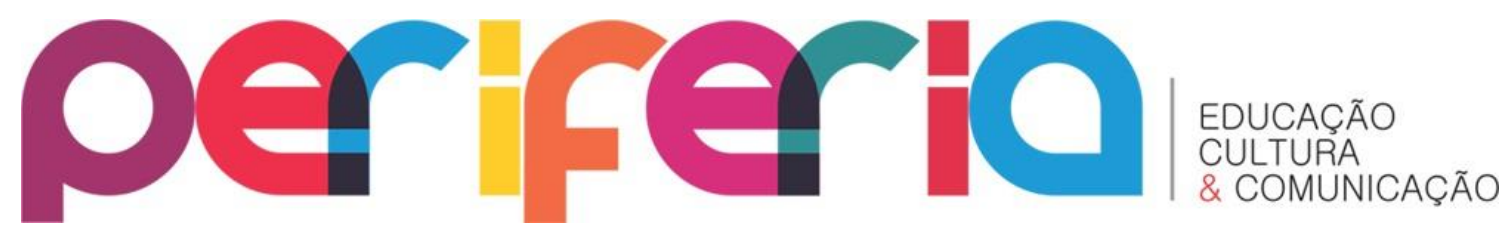

\section{REFERÊNCIAS}

ALBIERI, Sara. História Pública e consciência histórica. In: ALMEIDA, Juniele R. de; ROVAl, Marta G. de O. (orgs.). Introdução à História Pública. São Paulo: Letra e Voz, 2011. p. 19-28.

ARFUCH, Leonor. O espaço biográfico: dilemas da subjetividade contemporânea. Rio de Janeiro: EdUERJ, 2010.

BITTENCOURT, Circe Maria Fernandes. Ensino de História: fundamentos e métodos. São Paulo: Cortez, 2008.

CATROGA, Fernando. Memória, História e Historiografia. Coimbra: Quarteto, 2001.

GONÇALVES, Marcia de Almeida. Entre o local e o nacional: uma reflexão sobre éticas de pertencimento e identidades sociais. História de São Gonçalo: memória e identidade. $2001 . \quad$ Disponível em: <http://www.historiadesaogoncalo.pro.br/hp hsg lista artigos.htm>. Acesso em: 26 jan. 2014.

JELIN, Elizabeth. Los trabajos de la memória. Buenos Aires: Siglo XXI, 2002 (Colección Memorias de la Represión).

KELLEY, Robert. Public History: its origins, nature and prospects. In: LEFFLER, P.; BRENT, J. Public History readings. [S.I.]: Krieger, 1992. p. 111- 120.

LIDDINGTON, Jill. O que é história pública? In: ALMEIDA, Juniele R. de; ROVAI, Marta G. de O. (orgs.). Introdução à História Pública. São Paulo: Letra e Voz, 2011. p. 31-52.

NEVES, Joana. História local e construção da identidade social. Saeculum - Revista de História, João Pessoa, Departamento de História da Universidade Federal da Paraíba, no 3, p. 13-27, jan./dez. 1997.

POLLAK, Michael. Memória, esquecimento, silêncio. Estudos Históricos, Rio de Janeiro, v. 2, n. 3, p. 3-15, 1989.

. Memória e identidade social. Estudos Históricos, Rio de Janeiro, v. 5, n. 10, p.

200-212, 1992.

PUJOL, Javier Gil. Notas sobre el estudio del poder como nueva valoración de la historia política. Pedralbes, Barcelona, n. 3, p. 61-88, 1983.

SARLO, Beatriz. Tempo passado: cultura da memória e guinada subjetiva. Belo Horizonte: UFMG; Cia. das Letras, 2007.

SMITH, Richard Cándida. Circuitos de subjetividade: história oral, o acervo e as artes. São Paulo: Letra \& Voz, 2012.

SOARES, Olavo Pereira. Os currículos para o ensino de História: entre a formação, o prescrito e o praticado. Antíteses, v. 5, n. 10, p. 613-634, jul./dez. 2012. 